\title{
Effectiveness of Ball Exercises on Reduction of Stereotypic Behavior of Children With Autism Spectrum Disorder With High Performance
}

\author{
Gholamhosein Nazemzadegan $^{1}$, Aghdas Babadi ${ }^{1}, Z^{2}$ einab Zeinali ${ }^{1}$, Khalil Kakavandi ${ }^{2}$
}

1. Department of Physical Education, School of Education and Psychology, Shiraz University, Shiraz, Iran.

2. Department of Psychology and Education of Exceptional Children, School of Education and Psychology, Shiraz University, Shiraz, Iran.

Citation: Nazemzadegan GH, Babadi A, Zeinali Z, Kakavandi KH. Effectiveness of Ball Exercises on Reduction of Stereotypic Behavior of Children With Autism Spectrum Disorder With High Performance. Iranian Rehabilitation Journal. 2016; 14(2):121-126. https://oi.org/10.18869/nrip.irj.14.2.121

https://doi.org/10.18869/nrip.irj.14.2.121

\section{Article info:}

Received: 29 Nov. 2015

Accepted: 31 Mar. 2016

\section{Keywords:}

Ball exercises, Jim ball, Autism spectrum disorder, Stereotype behaviors

\begin{abstract}
Objectives: The incidence of stereotyped behaviors is one of the major symptoms of diagnosis of individuals with autism spectrum disorder that causes disruption in daily life. This study aimed at evaluating the effectiveness of ball exercises on the reduction of stereotypical behavior of children with autism spectrum disorder.

Methods: In this study, 16 children (boys) with autism spectrum disorder were randomly selected by purposive sampling and were assigned to two groups (experimental and control groups) with eight subjects each in both the. The ball exercise intervention program was implemented for 24 sessions ( 8 weeks, 3 sessions per week, each session lasting for $35 \mathrm{~min}$ ) for the experimental group. The control group participated in the occupational therapy activities similar to that of the experimental group for three times a week. The stereotyped behaviors were evaluated using a rating scale Gilliam ( $2^{\text {nd }}$ edition) and the end data were analyzed using analysis of covariance.
\end{abstract}

Results: Analysis of variance showed a significant difference in post-test scores of both the experimental and control groups $(\mathrm{P}=0.01)$, thus showing the effectiveness of the intervention.

Discussion: The results suggested that the Jim exercise ball could change the stereotypical behavior of children with high functioning autism spectrum disorder.

\section{Introduction}

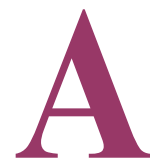

utism spectrum disorder is a type of dormant inability. Although people with autism look normal, they may possess strange and different behaviors and experience communication and specific social problems. It is a neuro-developmental disorder that has certain features, such as deficits in social communication, social interaction, and stereotypical behaviors [1].

Previous studies have detected the symptoms of autism spectrum disorder in the early years of growth before the age of three [2, 3]. Autism spectrum disorder is a biological disorder, but its genetic constitution is still not fully understood. People with autism show

* Corresponding Author:

Khalil Kakavandi, MA

Address: Department of Psychology and Education of Exceptional Children, School of Education and Psychology, Shiraz University, Shiraz, Iran. Tel: +98 (919) 2690393

E-mail: khalilkakavandi@gmail.com 
abnormalities in different areas of the brain, including frontal, parietal, cerebellum, amygdale, and hippocampal regions [4]. For children with autism, Conner [5] reported the following symptoms for children with autism: Loneliness, homelessness, failure to provide gesture-specific and expected physical developmental delay or echo-like repetition, inversion pronoun (use of the pronoun "you" instead of "I"), humdrum sound and words and excellent rote memory, restrictions on the types of automatic movements, behaviors and stereotyped gestures, insisting on uniformity and preventing any change in its environment, poor eye contact, having abnormal (with others, images and inanimate objects) and extreme reactions to environmental stimuli, unusual interest in some games and specific behaviors, cognitive and emotional problems [6], stereotyped behavior patterns, having disorders like hyperactivity, reduced attention, anxiety symptoms (especially, forms of obsessive-compulsive), and cognitive limitations or mental retardation (mild to severe).

The number of boys with this disorder is five times more than the girls. The Center for Disease Control and Prevention states that the prevalence of autism was 1 out of 150 children in 2007, in 2009 it was 1 out of 110 children in 2009 , and it was 1 out of 88 children in 2012, which represents a marked increase over the recent years [7]. Statistics of this disorder is different in different countries, but it shows a rising trend, although the shift from absolutism to the whole integration of this disorder may lead to discovering more cases of autism spectrum disorder. Children with autism spectrum disorder also have problems with communication skills as well (both verbal and written).

Stereotypical behavior is one of the main diagnostic symptoms in people with autism spectrum disorder [8]. These behaviors are said to be often repetitive, whereas the interests and motion sequences or expressions are apparently fixed in the pattern of implementation, followed by stimulation or compatibility [9]. It seems that the stereotypical behavior does not bring any threat to the patients, but the considerable disruption in the process of learning, acquisition of social skills, adaptation functions, and the process of sleep increases stress on the family, and their behavior becomes abusive. Thus, there is a need to determine methods and strategies to reduce and treat this behaviorcan be . Interventions associated with play and physical and motor activity has been one of the most promising methods of treating children with autism in the last 30 years ve [10-12].

The benefits of participation in physical activity and exercise in normal children [13] and children with de- velopmental disorders have also been discussed [14]. In this study, the effect of different types of motor activity, including running $[15,16]$, skating [17], swimming [18] and techniques of stretching and muscle contraction [19], and training hub [20] in reducing stereotypical behaviors of children with autistic disorders have been studied.

Ball training includes movements in which with or without the means the force is inserted into an object. Ball training can help to develop a variety of skills that includes eye-hand coordination, eye-foot coordination, manipulation of objects, chasing vision, coordination, body control, momentum, rhythm and timing, participation, attention, the speed of action, interaction with others and their relationship [21]. Ball training is considered a turning point in many games, and unlike some motor skills that are normally learned from the experience of general movements, it is learned from these skills. The skills mentioned above should also be taught to the children without developmental disabilities [22]. Ball training can be performed individually one by one or in groups and either organized or for recreation, which is considered important for social activities. Performing various movements on the training Jim ball leads to stimulation of the central nervous system and increases the blood flow to the brain. Research shows that motion causes brain consciousness and is, thus, more effective [23].

It seems that the ball training in association with, is the best way to facilitate the development of motor skills given its association with movement, thinking, competition, and entertainment. This is because games and quizzes are considered to be an important factor in the development of motor skills. This is particularly due to the lack of social experiences of children with autism, compared to the peer group that causes enrichment in their movement and social experiences to continue their lives independently. Other interventions based on ball training for the stereotypic behaviors of children with autism spectrum disorder require further research. The present study aims at ingdetermining whether Jim ball exercises are effective against the stereotypical behaviors of children with autism spectrum.

\section{Methods}

The research method was quasi-experimental with pretest-post-test and control group. Independent variables were Jim and regular ball exercises, and the dependent variable was the stereotypic behavior of children with autism spectrum disorder. was All male children with autism spectrum disorder, who were re- 
ferred to the center of Martyr Farzaghi in Shiraz, in 2014-2015, were considered for this study. Only 16 children were selected by accessible sampling The subjects and were randomly assigned to two groups with eight children each (test and control). Both the experimental and control groups were placed under the Jim ball intervention training for 24 sessions (12 weeks, 2 sessions of 45 minutes of exercise), and theindividual training sessions were conducted for each subject.

It is worth noting that before and after the intervention program, the stereotypic behavior interaction questionnaire was completed for both the control and experimental groups. In this study, Gilliam Autism Rating Scale tool-Second Edition [GARS-SE] [24], a norm-reference tool for the diagnosis and severity assessment rating of autism spectrum disorder, was approved by the Psychiatric Association of America to befor use. The first version of this scale was developed in 1995 [8]. The second version is based on the most widely accepted definition of autism spectrum disorders (according to DSM-IV-TR) and has been used by 1170 people, aged 3-22 years, and developed from 48 different states. This scale has three subscales of stereotyped behavior, communication, and social interaction with $14 \mathrm{~s}$ items for each category. Only two subscales of communication and social interaction were considered for the present study. GIRL-SE based on direct observation and interviews with parents and teachers of children with autism spectrum disorder were completed and widely used in educational programs and research. The caregivers were asked to rank their children's behavior based on the frequency of their occurrence in a six-hour time limit on a rating scale of zero to four values (see non-desired behavior) to three (see repeated behav- ior). The raw score of stereotypical behavior was converted to standard scores with a mean of 10 and a standard deviation of 3. Cronbach's alpha coefficient of its Persian version [25] in Isfahan has been reported as 0.89 , and the constructed validity with the modified list in childhood autism (MCAT) for subscales of stereotypic behavior and total scores were 0.84 and 0.88 , respectively.

\section{Results}

The demographic variables forsuch as age, weight and height, were described for all participants. The data for both the control and experimental groups were collected and have been presented in Table 1. Table 2 shows the mean and standard deviation of the dependent variable in the process of measurementhave been.

In Table 2, it that there are differences between the experimental and control groups in pre-test and post-test. In order to test this difference and determine that the obtained changes are statistically significant, the analysis of covariance was used. Before regression analysis of covariance, homogeneity of variances was determined (Levene test), and the condition of the normal distribution of the dependent variables was evaluated using a statistical test Kolmogorov-Smirnov test. The results showed that the distribution of all the dependent variables in both the experimental and control groups was normal $(\mathrm{P}>0.05)$.

The results of covariance analysis after statistically controlling the effect of pre-test showed no statistically significant difference in test scores between the experimental and control groups $(\mathrm{P}>0.01, \mathrm{~F}=(95.30) \mathrm{df}=14)$.

Table 1. Mean \pm standard deviation of age, height and weight.

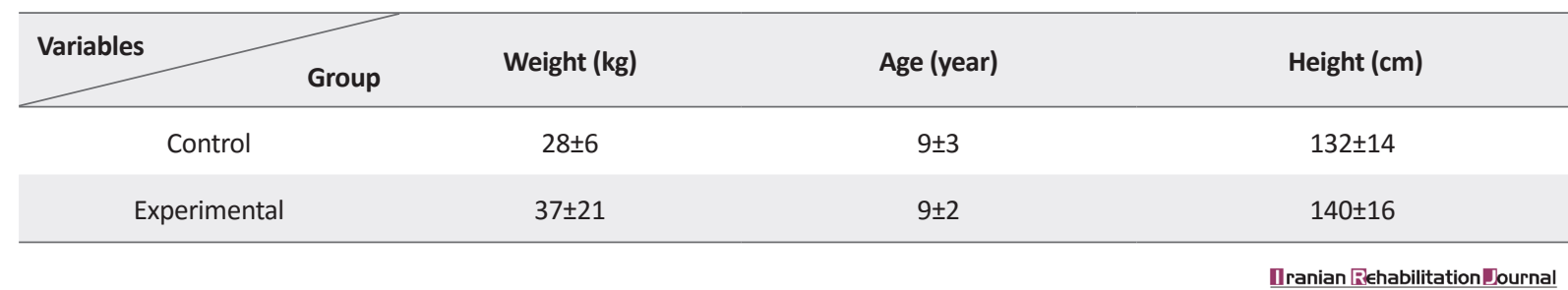

Table 2. Mean and standard deviation of stereotyped behavior in both the control and experimental groups.

\begin{tabular}{cccccc}
\hline & & \multicolumn{3}{c}{ Pretest } & \multicolumn{2}{c}{ Posttest } \\
\cline { 3 - 6 } Variables & Group & M & SD & M & SD \\
\hline \multirow{2}{*}{ Stereotyped behavior } & Experimental & 15.75 & 7.22 & 14.37 & 6.94 \\
& Control & 17 & 6.74 & 17.37 & 6.71 \\
\hline
\end{tabular}


Thus, this indicates that the intervention has been effective. In other words, ball training (Jim ball) caused the change in the stereotypical behavior of children with high functioning autism spectrum disorder.

\section{Discussion}

Our results indicated the effectiveness of ball training on the stereotyped behavior of the participants. These findings are consistent with the results of other studies $[18,20,26-29]$. The exact mechanism of the effect of physical activities on stereotypical behavior is still unclear. Different experts and researchers in this field have offered various explanations in this regard [30]. According to some researchers, motor activity is considered as an efficient tool that influences stereotypical behaviors by providing similar sensory feedbacks. More appropriately, this interpretation supports the operating model that justifies the creation and maintenance of stereotyped gestures in children with autism spectrum disorder.

According to this justification, the stereotyped behaviors generated through sensory feedback will be retained after performing these gestures, and such movements may be replaced or eliminated by gestures that create similar feedback [31]. Hence, the study shows that the overlap between the taught movements and format movements was found to be more, and the impact of these movements in reducing or eliminating stereotypes was also more [32]. Some researchers have considered the onset of fatigue after physical activity to be effective in reducing stereotypes [33]. However, based on athe motor activity of autistic children as well as reducing stereotypes, it has been observed that the intervention increases positive behaviors (such as an improvement in academic assignments) among these children.

Optimal motivation theory is useful in interpreting the results of this study. Based on this theory, for any organism, there is an optimal level of motivation. Stereotypes applied to compensatory function increases the motivational level in less optimal situations and reduces their motivational level in over stimulating situations [34, 35]. In coordination with this theory, it can be assumed that the Jim ball exercises iveare effective in reducing stereotyped behaviors as they facilitate performance and adjust the incentives to the optimum level. Created in stereotyped behaviors persist, reduction of subjects in this study can be explained from the Nero-chemical perspective. In people with autism spectrum disorder, abnormalities have been detected in the functioning of neurotransmitters, such as serotonin and dopamine. This plays an important role in the incidence and main- tenance of stereotyped behaviors [36]. Also, the shortcomings have been observed in the metabolism of serotonin in people with autism spectrum disorders [37].

The negative relationship between pre serotonin expressive abilities and the harmful stereotyped behaviors by the subjects with autism spectrum disorder has been observed. On the other hand, motor activity possesses a major impact on the serotonin and dopamine systems [32]. In addition, a significant reduction has been shown in blood serotonin concentrations after the long-term motor engagement. Twisting, turning and sitting on a fitness ball at the same time stimulates the central nervous system and increases blood flow to the brain. Exercise increases the heart rate, leading to faster heartbeat, which in turn strengthens the heart muscle.

The circulatory system pumps blood (carrying oxygen to the muscles) efficiently and effectively because oxygen consumption increases during the exercise. In addition stated facts, other characteristics, i.e. the size of the ball and its features, such as color options, can be influenced by the stereotypes of children i.e. This type of training aspect of the game highlights the level of excitement, joy and entertainment. One of the advantages of this training is that the fun part of the exercise encourages people to use their exercise ball and do different movements [23].

\section{Conclusion}

In addition, due to easy handling, low cost, and low energy use of the ball and effort in training at all stages of treatment, this technique is highly effective for stereotyped children compared to other therapies based on physical activity (especially training hub). Therefore, it is recommended to consider these factors more seriously in the regulation of sports programs. The result of this study showed that Jim ball training is a normal and desirable activity for children with autism spectrum disorder and can cause a change in their stereotyped behavior. There is a need for further research to determine whether exercise reduces stereotyped behavioral mechanisms of autism spectrum children. It is also important and noteworthy to consider the program based on sports activities in the weekly program planned for the children.

\section{Acknowledgments}

The authors are very grateful to management of Shahid Farzaghi school, who helped the researcher in conducting and make it possible to use necessary facilities in the pro- 
cess of doing research. The current research hasn't received any financial support

\section{Conflict of Interest}

The authors declared no conflict of interests.

\section{References}

[1] American Psychiatric Association. Diagnostic and statistical manual of mental disorders. $5^{\text {th }}$ ed. Washington, D. C.: American Psychiatric Association; 2013.

[2] Horovitz M, Matson JL, Sipes M. The relationship between parents' first concerns and symptoms of autism spectrum disorders. Developmental Neurorehabilitation. 2011; 14(6):372-77. doi: 10.3109/17518423.2011.617322

[3] Lang R, Regester A, Lauderdale S, Ashbaugh K, Haring A. Treatment of anxiety in autism spectrum disorders using cognitive behavior therapy: A systematic review. Developmental Neurorehabilitation. 2010; 13(1):53-63. doi $10.3109 / 17518420903236288$

[4] Sternberg RJ. Cognitive psychology. $4^{\text {th }}$ ed. Belmont: Thomson Wadsworth; 2007.

[5] Kanner L. Autistic disturbances of affective contact. Journal of Nervous Child. 1943; 2:217-50.

[6] Zager D. Autism spectrum disorders,Identification, education and treatment. $3^{\text {rd }}$ ed. New York: Lawrence Erlbraum Associates Inc.; 2005.

[7] Centers for Disease Control and Prevention. Prevalence of autism spectrum disorders: Autism and Developmental Disabilities Monitoring Network, 11 Sites, United States, 2010. Surveillance Summaries. 2014; 63(2):1-24.

[8] Amerecan Psychiatric Association. Diagnostic and statistical manual ofmental disorder. $4^{\text {th }}$ ed. Washington, D. C.: American Psychiatric Association; 2000.

[9] Baumeister AA, Forehand R. Stereotyped acts. In: Ellis NR, editor. International Review of Research in Mental Retardation. New York: Academic Press; 1973, p. 55-96.

[10] Allison DB, Basile VC, MacDonald RB. Brief report: Comparative effects of antecedent exercise and clonazepam on the aggressive behavior of an autistic man. Journal of $\mathrm{Au}-$ tism and Developmental Disorders. 1991; 21(3):86-91. doi: $10.1007 /$ bf02207336

[11] Kern L, Koegel RL, Dyer K, Blew PA, Fenton LR. The effects of physical exercise on self-stimulation and appropriate responding in autistic children. Journal of Autism and Developmental Disorders. 1982; 12(4):399-419. doi: 10.1007/ bf01538327

[12] Levinson LJ, Reid G. The effects of exercise intensity on the stereotypic behaviours of individuals with autism. Adapted Physical Activity Quarterly. 1993; 10(3):255-68. doi: 10.1123 /apaq.10.3.255
[13] Harsha DW, Berenson GS. The benefits of physical activity in childhood. American Journal of the Medical Sciences. 1995; 310:109-13. doi: 10.1097/00000441-199512000-00019

[14] McGimsey JF, Favell JE. The effects of increased physical exercise on disruptive behaviour in retarded persons. Journal of Autism and Developmental Disorders. 1998; 18(2):167-79. doi: 10.1007/bf02211944

[15] Celiberti DA, Bobo HE, Kelly KS, Harris SL, Handleman JS. The differential and temporal effects of antecedent exercise on the self-stimulatory behavior of a child with autism. Research Developmental Disabilites. 1977; 18(2):139-50. doi: 10.1016/s0891-4222(96)00032-7

[16] Kern L, Koegel RL, Dunlap G. The influence of vigorous versus mild exercise on autistic stereotyped behaviors. Journal of Autism and Developmental Disorders. 1984; 14(1):5767. doi: $10.1007 /$ bf02408555

[17] Powers S, Thibadeau S, Rose K. Antecedent exercise and its effects on self-stimulation. Behavioral Interventions. 1992; 7(1):15-22. doi: 10.1002/bin.2360070103

[18] Yilmaz I, Yanardag M, Birkan BA, Bumin G. Effects of swimming training on physical fitness and water orientation in autism. Pediatric International. 2004; 46(5):624-26. doi: 10.1111/j.1442-200x.2004.01938.x

[19] Reid PR, Factor DC, Freeman NL, Sherman J. The effects of physical exercise on three autistic and developmentally disordered adolescents. Therapeutic Recreation Journal 1998; 22(2):47-56.

[20] Jekan M, Hoseini SA, Mohammadi MR, Salehi M. [The effect of ball skills training on adaptive behaviors of children with high functioning Autism (Persian)]. Journal of Rehabilitation. 2013; 2(13):48-56.

[21] Drew S, Atter E. Can't play won't play simply sizzling ideas to get the ball rolling for children with Dyspraxia. London: Jessica Kingsley Publication; 2008.

[22] Doty AK, McEwen IR, Parker D, Laskin J. Effects of testing context on ball skill performance in 5-year-old children with and without developmental delay. Physical Therapy. 1999; 79(9):818-26. PMID: 10479782

[23] Spalding A, Kelly LE. Fitness on the ball: A core program for brain and body. Champaign, I. L.: Human Kinetics; 2009.

[24] Gilliam JE. GARS-2: Gilliam autism rating scale. $2^{\text {nd }}$ ed. Austin, T. X.: Pro-Ed Inc.; 2006

[25] Ahmadi J, Safari T, Hematian Z. [The psychometrics properties of Gilliam autism rating scale (Persian)]. Researches of Cognetive Behavioral Sciences. 2012; 1(1):1-10.

[26] Karim AEA, Mohammed AH. Effectiveness of sensory integration program in motor skills in children with autism. Egyptian Journal of Medical Human Genetics. 2014; 16(4):375-80. doi: 10.1016/j.ejmhg.2014.12.008

[27] Li S, Lou K, Tsai H, Shih R. The effects of applying gamebased learning to webcam motion sensor games for autistic students' sensory integration training. Turkish Online Journal Education Technology. 2012; 11(4):451-59.

[28] Pfeiffer BA, Koenig K, Kinnealey M, Sheppard M, Henderson L. Effectiveness of sensory integration interventions in children with autism spectrum disorders: A pilot study. 
American Journal of Occupational Therapy. 2011; 65(1):7685. doi: 10.5014/ajot.2011.09205

[29] Elliott RO, Dobbin AR, Rose GD, Vigorous HVS. Aerobic exercise versus general motor training activities: Effects on maladaptive and stereotypic behaviors of adults with both autism and mental retardation. Journal Autism Developmental Disorders. 1994; 24(5):565-76. doi: 10.1007/ bf02172138

[30] Lanovaz MJ. Towards a comprehensive model of stereotypy: Integrating operant and neurobiological interpretations. Research in Developmental Disabilites. 2011; 32(2):447-55. doi: 10.1016/j.ridd.2010.12.026

[31] Berkson G. Repetitive stereotyped behaviours. American Journal of Mental Deficiency. 1983; 88:239-46.

[32] Watters RG, Watters WE. Decreasing self-stimulatory behavior with physical exercise in a group of autistic boys. Journal of Autism and Developmental Disorders. 1980; 10(4):379-87. PMID: 6927742

[33] Tarnowski KJ, Drabman RS. The effects of ambulation training on the self-stimulatory behavior of a multiply handicapped child. Behavior Therapy. 1985; 16(3):275-85. doi: 10.1016/s0005-7894(85)80015-0

[34] Berlyne DE. Conflict, arousal and curiosity. New York: McGraw-Hill; 1960.

[35] Hebb DO. Drives and the C.N.S. (Conceptual nervous system). Psychology Review. 1955; 62(4):243-54. doi: $10.1037 / \mathrm{h} 0041823$

[36] Kolevzon A, Newcorn JH, Kryzak L, Chaplin W, Watner D, Hollander E, et al. Relationship between whole blood serotonin and repetitive behaviors in autism. Psychology Research. 2010; 175(3):274-76. doi: 10.1016/j.psychres.2009.02.008

[37] Schmidt GJ. Aerobic exercise related to functional aerobic capacity, repetitive/interfering behavior, and platelet serotonin concentration of individuals with autism $[\mathrm{PhD}$ dissertation]. Bloomington: Indiana University Bloomington 1989. 